\title{
Alternativo
}

\section{A EDUCAÇÃO SOB A ÓTICA FREUDIANA}

Débora dos Santos Silva (1)

\begin{abstract}
Resumo
A educação é um tópico por demais importante nas considerações dos homens interessados na ciência: através dela toda a civilização vai reconstruindo a aprendizagem e melhorando as técnicas e formas de compreensão. Sigmund Freud enquanto pensador, inclinado às considerações universalistas, não fugiu a esta condição, apesar de não ter sistematizado suas idéias a este respeito. Portanto, iremos tratar neste trabalho de alguns textos freudianos no intuito de trazer à luz suas opiniões no tocante às peculiaridades do ato de educar e de ser educado. Para realizar esta proposta utilizaremos, também, textos de alguns autores psicanaliticamente norteados.
\end{abstract}

Palavras-chave: psicanálise, educação, Freud, repressão, sublimação, neurose.

\section{Introdução}

Sigmund Freud (1856-1939) foi um intelectual profundamente comprometido com a busca da verdade, verdade esta que somente o olhar científico poderia indicar. Porém, “(...) a ciência de que Freud falava não é, evidentemente, unicamente a ciência positiva; é todo o saber que visa unicamente à verdade. E a psicanálise faz parte dela" (MANNONI; 1993169). Assim, a psicanálise esteve desde seus primórdios a serviço da verdade que o olhar atento, observador e fluido ${ }^{1}$ faz revelar.

\footnotetext{
${ }^{1}$ Fluido no sentido de não cristalizado; quer dizer, não arraigado em hipóteses a priori. 
Foi por esta devoção pela verdade que Freud foi mal interpretado nos círculoscientíficos de sua época. Má interpretação que persiste ainda hoje, mesmo com a popularização da teoria freudiana; pois, se no passado a resistência se utilizava de argumentos morais e éticos para combater a análise, hoje, ela se apropria dos conceitos psicanalíticos para distorcê-los, fomentando ações inconseqüentes.

Esclareçamos melhor esta idéia!

A psicanálise que, antes, era repudiada por revelar o inconsciente enquanto morada de desejos incestuosos, parricidas, egoístas e perversos (e cerne do proceder do homem adulto não passando, portanto, de repetições e substituições de experiências da primeira infância, demonstrando ser a criança um verdadeiro perverso-polimorfo e não a criatura angelical e doce que se acreditava), atualmente, é incorporada nos discursos cotidianos de maneira a desculpar ações irracionais que o sujeito venha a praticar.

Queremos afirmar, dessa maneira, que Freud não apregoou a promiscuidade e o erotismo, ao contrário, se lembrarmos um pouco a sua teoria, logo, virá em nossas mentes os dois princípios que regem o aparelho mental: o princípio de prazer e o princípio de realidade. Ora,

(...) o ego descobre que lhe é inevitável renunciar à satisfação imediata, adiar a obtenção de prazer, suportar um pequeno desprazer e abandonar inteiramente determinadas fontes de prazer. Um ego educado dessa maneira tornou-se "racional"; não se deixa mais governar pelo princípio de prazer, mas obedece ao princípio de realidade que, no fundo, também busca obter prazer, mas prazer que se assegura levando em conta a realidade, ainda que seja um prazer adiado ou diminuído (FREUD, 1996, p.360). (Grifo do autor)

Portanto, ao constatar esta forma de como o ego lida com as exigências do id: que quer obter prazer não importa o tempo ou espaço, e da realidade: que precisa proibir e punir (as instituições sociais materializam bem esta realidade) para assegurar o convívio entre os homens fica nítido o objetivo da psicanálise, a saber: trazer os afetos, idéias e representações inconscientes para o terreno da consciência de modo que possam ser trabalhadas e interpretadas pelo próprio sujeito, objetivando transformar a infelicidade neurótica deste indivíduo em infelicidade comum (não-incapacitante). Logo, pode-se dizer que Freud nunca 
quis desculpar os impulsos hostis e sexuais do homem, mas sim, identificá-los, interpretá-los e direcioná-los através de uma razão sábia.

(...) à semelhança de Rouanet, Freud defende uma razão sábia, esclarecida, capaz de contemplar a dimensão pulsional (ou passional) do ser humano, caso contrário concorrerá para sua própria destruição. (AMARAL; ISSN:1415-5486;p.32)

Depois dessa defesa apaixonada a respeito da visão de homem que Freud possuía, defesa que, em última instância se justifica considerando a nossa própria interpretação de homem, voltemos; ou melhor, iniciemos no tópico proposto para este trabalho, a saber: quais as contribuições de Freud para o campo da educação. Vejamos!

\section{Como a psicanálise chega ao tema Infância}

A psicanálise surge na clínica médica, empregada para a cura ou alívio dos problemas da histeria em adultos. Freud, no decorrer dos atendimentos que prestava foi percebendo que explicar a gênese das doenças psíquicas (nestes adultos) a partir da manifestação dos sintomas não era suficiente para o estudo e entendimento dos casos psicopatológicos. Assim, ele foi sendo obrigado a reconhecer nos traumas e fantasias da infância a origem dos problemas posteriores. E, dessa maneira, “(...) a psicanálise trouxe à luz os desejos, as estruturas de pensamento e os processos de desenvolvimento da infância (...)" (FREUD; 1996, p.190).

Além disso, as descobertas feitas levaram a uma nova maneira de compreender a infância, maneira que suscita de início grande incredulidade por parte daquele que se depara com os estudos psicanalíticos, e, que se explica pelo fato de nós adultos experimentarmos uma espécie de amnésia infantil que nos impede de trazer à consciência as situações vivenciadas em nossos primeiros anos. Esta atitude, portanto, é bem compreensível. Como não poderia ser diferente, esta incredulidade também é manifestada por parte dos educadores.

Quando, porém,

(...) os educadores se familiarizarem com as descobertas da psicanálise, será mais fácil se reconciliarem com certas fases do desenvolvimento infantil e, entre outras coisas, não correrão o risco de superestimar a 
importância dos impulsos instintivos socialmente imprestáveis ou perversos que surgem nas crianças (...). (FREUD; 1996, p.191)

Com essas palavras, Freud vem alertar para a necessidade de se conhecer o objeto de nossa influência educacional - a criança - de modo a se estar bem situado a respeito de cada fase do desenvolvimento infantil. Ademais, a ênfase dada por parte do educador para inibir, proibir e suprimir os impulsos associais serão, com uma educação psicanaliticamente esclarecida, dirigidos para outros fins. É assim que, esses impulsos perversos e aparentemente imprestáveis poderão ser “(...) desviados de seus objetivos originais para outros mais valiosos, através do processo conhecido como 'sublimação,2 (...)”. (IDEM; p.191).

No entanto, se o educador não reflete sobre estes pontos e, continua agindo mediante resistência e negação destes impulsos infantis, poderá, quando em sala de aula suprimi-los pela força ${ }^{3}$, o que conduzirá à repressão. Repressão que provou ser uma das principais causas de adoecimento psíquico no futuro.

\section{Missão do educador}

Segundo Mannoni (1993), Freud em "Leonardo da Vinci e uma lembrança da sua infância" (1910) irá apontar que a pulsão epistemológica, ou seja, a necessidade de conhecer, de saber, não passa de um protótipo da curiosidade da criança ante o enigma da sexualidade. Assim,

(...) essa pulsão, a partir dessa forma infantil, pode seguir três caminhos, ter três 'destinos': 1.Pode permanecer inibida, a inteligência se detém em seu desenvolvimento, chega-se à estupidez, ao retardo mental. 2. Prossegue na forma de atividade, mas não se desprende de seu primeiro objeto, permanece sexualizada. O trabalho intelectual, então, é acompanhado dos prazeres, das angústias, da culpa, das perversões próprias à esfera sexual. A investigação continua, mas seus resultados não têm o valor que deveriam ter (...) 3. A pulsão é sublimada (se desprende do fim sexual), e a

\footnotetext{
${ }^{2}$ Que nada mais é que o desvio da energia libidinal das pulsões parciais de sexualidade para realizações socialmente valoradas.

${ }^{3}$ Claro que esta força a qual nos reportamos não é a física, e sim, a psíquica.
} 
curiosidade opera livremente a serviço de interesses intelectuais autênticos (...). (MANNONI; Op.Cit.; p.142-43) (Grifo do autor)

Diante desses três destinos que poderá ter a pulsão epistemológica, podemos perceber a importante tarefa do educador junto às crianças. Tarefa que precisa ser bem trabalhada se, se pretende fazer dos infantis, futuros cidadãos a salvo, no que a educação pode realizar da neurose.

Em "Explicações, aplicações e orientações" Freud irá dizer que a tarefa primeira da educação é adaptar a criança às exigências sociais; além de repassar à mesma os resultados de uma evolução cultura milenar. Já que,

(...) É impossível conceder-lhe liberdade de pôr em prática todos os seus impulsos sem restrição (...) a vida seria impossível para os pais, e as próprias crianças sofreriam um grave prejuízo, que se exteriorizaria, em parte, imediatamente, e, em parte, nos anos subseqüentes (...). (FREUD; 1996; p.147)

No entanto, há de se buscar um ponto ótimo em que a educação possa realizar o máximo de êxito com um mínimo de dano ao ego imaturo da criança. Deve-se atentar para o momento certo de proibir determinadas atitudes da criança, dar-lhe a medida certa de amor resguardando um grau eficaz de autoridade, e, principalmente, atentando para as disposições constitucionais inatas de cada criança que se busca exercer influência. Só assim o educador poderá movimentar o desejo de saber, a vontade de conhecer a respeito da história de nossos ancestrais, a respeito dos êxitos das ciências, da maravilha das artes e das diversas organizações religiosas.

Enfim, somente através do despertar do desejo: despertar ocasionado pelas relações transferenciais e contratransferenciais que a situação escolar também faz levantar dos escombros do inconsciente, é que a tarefa de conduzir as mentes imaturas das crianças para uma atividade verdadeiramente intelectual e livre de neuroses ${ }^{4}$ poderá ser efetivada. Para tanto, o educador, como o próprio Freud sugeriu, deveria passar por uma sólida formação analítica, onde o analista poderia “(...) trabalhar a transferência do mestre em relação à

\footnotetext{
${ }^{4} \mathrm{Na}$ medida em que for possível, pois “(...) o conflito entre as pulsões de vida e a pulsão de morte não é apenas inevitável, mas também incontrolável. Ou seja, tanto é impossível prever ou garantir um certo estado psíquico num momento posterior(...)".(Ver LAJONQUIÈRE em "Educação, religião e cientificismo";ISSN:14155486;pp.20-1)
} 
educação (...)” ajudando-o “(...) a conhecer as fantasias com as quais ele se veste e é vestido" (BACHA; ISSN:1415-5486; p. 65) pelos alunos.

Por falar em alunos, gostaríamos, para encerrar nossa discussão, de citar algumas palavras que Freud redigiu em homenagem ao $50^{\circ}$ aniversário de fundação do Sperlgymnasium; colégio em que estudou dos nove aos dezessete anos. Neste texto, irá relembrar do tempo em que era aluno, de como seu espírito era invadido por grandes esperanças ao deparar-se com os primeiros vislumbres de uma civilização extinta e como sua relação com os mestres era atravessada por sentimentos ambivalentes que não tinham nenhuma base na realidade objetiva. Escolhemos esta citação por acreditarmos resumir o que vínhamos tratando até este momento, além de demonstrar o quanto a personalidade do professor interfere ou estimula o desejo de saber dos discentes. A oração é extensa, porém, merece ser citada:

(...) Minha emoção ao encontrar meu velho mestre-escola adverte-me de que antes de tudo, devo admitir uma coisa: é difícil dizer se o que exerceu mais influência sobre nós e teve importância maior foi a nossa preocupação pelas ciências que nos eram ensinadas, ou pela personalidade de nossos mestres. É verdade, no mínimo, que esta segunda preocupação constituía uma corrente oculta e constante em todos nós e, para muitos, os caminhos das ciências passavam apenas através de nossos professores (...).

(...) Nós os cortejávamos ou lhes virávamos as costas; imaginávamos neles simpatias e antipatias que provavelmente não existiam; estudávamos seus caráteres e sobre estes formávamos ou deformávamos os nossos. Eles provocavam nossa mais enérgica oposição e forçavam-nos a uma submissão completa; bisbilhotávamos suas pequenas fraquezas $e$ orgulhávamo-nos de sua excelência, seu conhecimento e sua justiça. No fundo, sentíamos grande afeição por eles, se nos davam algum fundamento para ela, embora não possa dizer quantos se davam conta disso. Mas não se pode negar que nossa posição em relação a eles era notável, uma posição que bem pode ter tido suas inconveniências para os interessados. Estávamos, desde o princípio, igualmente inclinados a amá-los e a odiá-los, a criticá-los e a respeitá-los. (FREUD; 1996; p.248). 
Essas palavras suscitam profundas reflexões por parte de nós estudantes. A sabedoria com que Freud descreve a sua situação enquanto escolar nos faz estremecer diante de tamanha capacidade de interpretação. Este estremecimento talvez resulte de uma espécie de identificação... Realmente nos sentimos, ante nossos mestres, assaltados por sentimentos contraditórios: ódios e amores que não se fundamentam na relação que travamos com eles, mas, que são isto $\operatorname{sim}(!)$ repetições ${ }^{5}$ de relações vivenciadas em nossa infância com os primeiros objetos de nosso amor. Sendo, portanto, nossos professores, figuras substitutivas de nossos pais (e/ou babás), enfim...

\section{Considerações finais}

Pretendemos, neste estudo, repassar um pouco de nosso aprendizado no tocante à relação entre psicanálise e educação. Longe de ter esgotado as questões a este respeito ou de ter trazido à baila um tema novo, acreditamos que pudemos contribuir para um melhor entendimento desta relação (psicanálise e educação); pois, muito embora, não se encontre explicitamente nos textos de Freud preocupações dirigidas à aprendizagem, é sabido que este tópico figurava em seus pensamentos: se considerarmos algumas de suas colocações no que tange ao problema da profilaxia das neuroses.

Ademais, esperamos que o assunto trabalhado ao longo do texto possa ter despertado uma curiosidade: curiosidade de ler a obra de Freud, obra repleta de cultura, arte, medicina, psicologia, história, literatura, arqueologia; enfim, cheia de conhecimentos e observações relevantes à nossa civilização.

\section{Bibliografia}

AMARAL, Monica G.T. do; O limite da fronteira freudiana; In: Educação; Especial: Freud pensa a educação; ISSN: 1415-5486; Vol. 1.

BACHA, Marcia Simões Corrêa Neder; O mestre e seus Feitiços; In. Revista Educação; Especial: Freud pensa a educação; ISSN:1415-5486; Vol.1.

\footnotetext{
${ }^{5}$ A nível alucinatório, posto não ser real. 
CAMPOS, Dinah Martins de Souza; Teorias Psicodinâmicas da Aprendizagem. In: Psicologia da Aprendizagem; Petrópolis: Vozes, 2007; 36 Ed.

FREUD, Sigmund; O interesse educacional da psicanálise; Trad. José Luís Meurer; In: Totem e tabu e outros trabalhos; Rio de Janeiro: Imago,1996; Vol. XIII; Obras completas. ; Algumas reflexões sobre a psicologia do escolar; Trad. José Luís Meurer; In: Totem e tabu e outros trabalhos; Rio de Janeiro: Imago,1996;Vol. XIII; Obras completas.

; Os caminhos para a formação dos sintomas; Trad. José Luís Meurer; In:

Conferências introdutórias sobre psicanálise; Rio de Janeiro: Imago,1996; Vol.XVI, Obras completas (Parte III) ; Explicações, aplicações e orientações; Trad. José Luís Meurer; In: Novas

Conferências introdutórias sobre psicanálise e outros trabalhos; Rio de Janeiro: Imago, 1996; Vol.XXII; Obras completas.

LAJONQUIÈRE, Leandro de; Educação, religião e cientificismo; In: Revista Educação; Especial: Freud pensa a educação; ISSN:1415-5486;Vol.1.

MANNONI, Octave; Trad. Maria Luiza X. de A. Borges; Cronologia; In: Freud, uma biografia ilustrada; Rio de Janeiro: Jorge Zahar Ed.,1994.

PINTO, Manuel da Costa (Org.); O Livro de ouro da psicanálise: o pensamento de Freud, Jung, Melanie Kein, Lacan, Winnicott e outros; Rio de Janeiro: Ediouro, 2007; $2^{\circ}$ Ed.

Sobre a autora:

(1) Débora dos Santos Silva é acadêmica de Psicologia da Faculdade Leão Sampaio, Juazeiro do Norte-CE. E-mail: djuziro@hotmail.com 